University of Nebraska - Lincoln

DigitalCommons@University of Nebraska - Lincoln

May 2001

\title{
Solid Phase Extraction Gas Chromatography/Electron Capture Detector Method for the Determination of Organochlorine Pesticides in Wildlife Whole Blood
}

\author{
S. A. Volz \\ USDA National Wildlife Research Center \\ J.J. Johnston \\ USDA/APHIS/WS/National Wildlife Research Center \\ D.L. Griffin \\ USDA/APHIS/WS/National Wildlife Research Center
}

Follow this and additional works at: https://digitalcommons.unl.edu/icwdm_usdanwrc

Part of the Environmental Sciences Commons

Volz, S. A.; Johnston, J.J.; and Griffin, D.L., "Solid Phase Extraction Gas Chromatography/Electron Capture Detector Method for the Determination of Organochlorine Pesticides in Wildlife Whole Blood" (2001). USDA National Wildlife Research Center - Staff Publications. 574.

https://digitalcommons.unl.edu/icwdm_usdanwrc/574

This Article is brought to you for free and open access by the U.S. Department of Agriculture: Animal and Plant Health Inspection Service at DigitalCommons@University of Nebraska - Lincoln. It has been accepted for inclusion in USDA National Wildlife Research Center - Staff Publications by an authorized administrator of DigitalCommons@University of Nebraska - Lincoln. 


\title{
Solid Phase Extraction Gas Chromatography/E lectron Capture Detector Method for the Determination of Organochlorine Pesticides in Wildlife Whole Blood
}

\author{
S. A. Volz,* J . J . J ohnston, and D. L. Griffin \\ USDA/APHIS/WS/National Wildlife Research Center, 4101 West La Porte Avenue, \\ Fort Collins, Colorado 80521
}

\begin{abstract}
A gas chromatographic method for the analysis of 10 organochlorine pesticides in $0.5 \mathrm{~mL}$ of whole blood is described. Sample preparation involved an ethyl ether and hexane extraction, followed by a silica solid phase extraction cleanup. The pesticides are quantified by gas chromatography/el ectron capture detection. Method limits of detection ranged from 1.1 to $5.2 \mu \mathrm{g} / \mathrm{L}$. The mean and standard deviation for the recovery of 10 pesticides was $97.9 \pm 5.5 \%$. Recoveries from whole blood were comparable to recoveries from plasma. This indicates that the preparation of plasma is unnecessary for the quantification of organochlorine pesticides in blood. This approach is particularly useful as a nonlethal approach for monitoring pesticide contamination in small animals for which the volume of blood is limiting.
\end{abstract}

Keywords: Solid phase extraction; dieddrin; organochlorine pesticides; capillary gas chromatography; whole blood; plasma

\section{INTRODUCTION}

The literature on the determination of organochlorine pesticides (OCPS) in human blood indicates that most investigators prepared sera or plasma from whole blood prior to extraction (1-4). In recent work performed in our laboratory for bi omonitoring at the Rocky Mountain Arsenal (RMA), we analyzed numerous wildlife plasma samples for OCPs. The main OCP contaminant on the arsenal was dieldrin, likely due to a pesticide production facility that previously occupied the site. In addition to dieldrin, biomonitoring was performed for aldrin, isodrin, heptachlor epoxide, trans-chlordane, cis-chlordane, $p, p^{\prime}-D D E$, endrin, and p, $p^{\prime}-D D T$.

All pesticide manufacturing operations on the RMA ceased in 1982. In 1987 cleanup of the RMA was initiated. The arsenal is now being remediated for public use and has been designated a National Wildlife Refuge. As part of the remediation and restoration process, biomonitoring of many wildlife species is ongoing. Whenever possible, nonlethal sampling approaches are preferred. In support of this effort, methodology for the quantification of OCPs in wildlife plasma was developed by our laboratory (5). Local and migratory birds have become a major issue for monitoring of the RMA. Obtaining adequate blood samples is difficult with some birds; therefore, plasma analysis is not the best approach for long-term biomonitoring of OCPs due to the potentially small sample size. To overcome this sample size obstacle inherent in the plasma method, we developed a method for the analysis of OCPs in $0.500 \mathrm{~mL}$ of whole blood stabilized with the anticoagulant heparin. The performance of the new whole blood method with the previous plasma method (5) were compared by fortifying whole blood at $50 \mathrm{ppb}$ using a mixed standard of 10 different OCPs and simultaneously extracting whole blood and plasma. The plasma was obtained by centrifuging fortified whole blood, which was then extracted using the plasma method (5), whereas whole blood samples were analyzed using the new methodology described in this paper.

\section{MATERIALS AND METHODS}

Equipment. A Hewlett-Packard (HP) (Palo Alto, CA) model 5890 series II gas chromatograph equipped with electronic pressure control, dual electron capture detectors, and dual 7673A autosamplers was used to quantify organochlorine pesticides in blood extracts. Solid phase extraction columns (SPE) contained $1 \mathrm{~g}$ of silica in a $3-\mathrm{mL}$ reservoir, and Vacmaster sample processing stations were from J ones Chromatography (Lakewood, CO). Gas chromatography (GC) expendables used included inlet liners, silanized glass wool, and gold inlet seals and were from Restek Corp. (Bellefonte, PA).

Chemicals. Organochlorine pesticide standard solutions for lindane, aldrin, isodrin, heptachlor epoxide, trans-chlordane, cis-chlordane, dieldrin, p, $p^{\prime}-D D E$, endrin, and p, $p^{\prime}$-DDT were obtained from both Chem Service Inc. (West Chester, PA) and Supelco (Bellefonte, PA). Ether, anhydrous 99+\%, was from Aldrich Chemical Co. (Milwaukee, WI). Pesticideresidue grade hexane was from Burdick \& J ackson (Muskegon, MI). Acetone was from Fisher Scientific (Pittsburgh, PA). Control chicken whole blood stabilize with heparin was obtained from Animal Technologies, Inc. (Tyler, TX).

Standard Preparation. A mixed standard was prepared by combining aliquots of each standard solution and diluting with acetone $(10.0 \mu \mathrm{g} / \mathrm{mL})$. This was diluted in acetone to prepare standard solutions for fortification (1.00 and $0.500 \mu \mathrm{g} /$ $\mathrm{mL}$ ). I nstrument calibration standards and diluted standard solution were prepared in hexane.

Sample Fortification. Control blood was fortified with a mixed standard containing lindane, aldrin, isodrin, heptachlor epoxide, trans-chlordane, cis-chlordane, $p, p^{\prime}-D D E$, dieldrin, endrin, and p,p'-DDT. F or method validation, control blood was fortified at six levels: $25,50,100,250$, and $500 \mu \mathrm{g} / \mathrm{L}$ of each compound; the blank was fortified at $250 \mu \mathrm{g} / \mathrm{L}$ with only the surrogate (lindane). Lindane was chosen as a surrogate because of its similarities to the analytes of interest and there was no prior use of lindane at this site. 


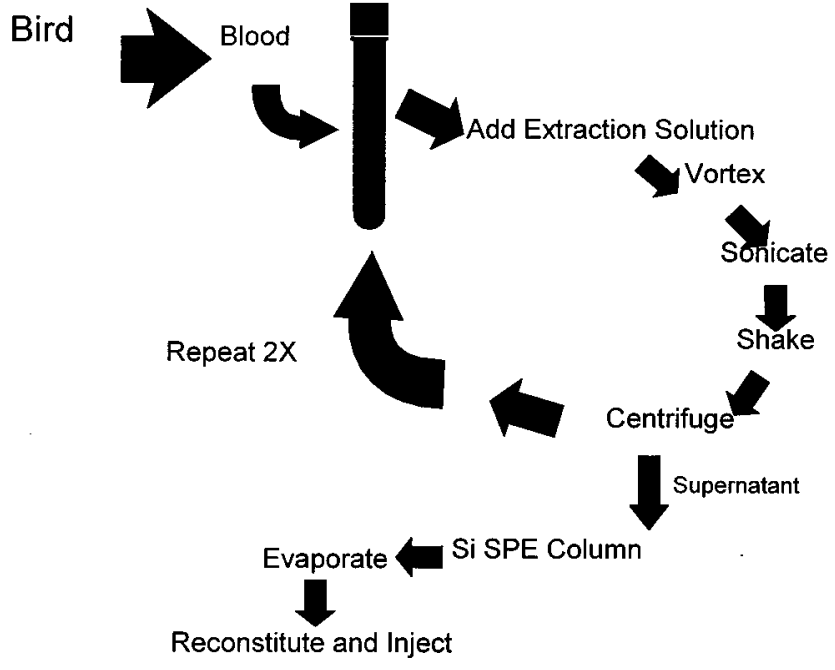

Figure 1. Flow chart of procedure.

Sample Preparation. As summarized in Figure 1, a 0.500 $\mathrm{mL}$ aliquot of homogeneous blood was transferred to a $10-\mathrm{mL}$ glass centrifuge tube, fortified, and allowed to equilibrate for $1 \mathrm{~h}$. The analytes were extracted from the blood using two 3- $\mathrm{mL}$ aliquots of ethyl ether followed by one 3- $\mathrm{mL}$ aliquot of 50:50 hexane/ether, vortex mixed, sonicated for $10 \mathrm{~min}$, hand shaken for $1 \mathrm{~min}$, and centrifuged for $2 \mathrm{~min}(\approx 1400 \mathrm{~g})$. The extract was carefully transferred to a silica SPE and loaded onto the sorbent with a low vacuum ( -0.05 to -0.1 bar). The pipet used for transferring the extract was rinsed onto the sorbent with 50:50 hexane/ether. To ensure all of the analytes of concern are not retained, the sorbent is rinsed with $4 \mathrm{~mL}$ of 50:50 hexane/ether. The entire eluate for each sample was collected in a clean 25-mL evaporation tube, which had been calibrated to a $0.500-\mathrm{mL}$ volume with hexane. The final amount of solvent in the column was removed under a gentle vacuum ( -0.2 bar). The total vol ume of extract should be $\sim 14$ $\mathrm{mL}$. The extracts were concentrated to $<0.500 \mathrm{~mL}$ under a gentle stream of nitrogen in a fume hood, equilibrated to room temperature, and brought to a final volume of $0.500 \mathrm{~mL}$ with hexane. The samples were then capped, vortex mixed, and transferred to GC vials for quantification of OCPs via GC analysis.

Gas Chromatography. The inlet temperature was $250^{\circ} \mathrm{C}$, and the detector temperature was $350^{\circ} \mathrm{C}$. The GC parameters were controlled utilizing HP ChemStation software and an HP Vectra XM series 3 computer. The carrier gas was helium (3 $\mathrm{cm} / \mathrm{s})$, and the makeup gas was argon/methane $(60 \mathrm{~mL} / \mathrm{min})$. The quantitation column was a $30 \mathrm{~m} \times 0.25 \mathrm{~mm}$ i.d. fused silica, HP-5 cross-linked 5\% phenyl methyl silicone stationary phase, $0.25-\mu \mathrm{m}$ film thickness (Hewlett-Packard). The confirmation column was a $30 \mathrm{~m} \times 0.25 \mathrm{~mm}$ i.d. fused silica DB-17 cross-linked $50 \%$ phenyl methyl siloxane stationary phase, 0.15 $\mu \mathrm{m}$ film thickness ( $\&$ W Scientific, Folsom, CA).

The oven temperature program for quantitation and confirmation was as follows: $50^{\circ} \mathrm{C}$ for $0.25 \mathrm{~min}, 60^{\circ} \mathrm{C} / \mathrm{min}$ to $100{ }^{\circ} \mathrm{C}$, hold for $0 \mathrm{~min}, 15^{\circ} \mathrm{C} / \mathrm{min}$ to $190^{\circ} \mathrm{C}$, hold for $2 \mathrm{~min}, 10$ ${ }^{\circ} \mathrm{C} / \mathrm{min}$ to $230^{\circ} \mathrm{C}$, hold for $11 \mathrm{~min}, 60^{\circ} \mathrm{C} / \mathrm{min}$ to $300^{\circ} \mathrm{C}$, hold for $8.58 \mathrm{~min}$. The electronic pressure program for the quantitation column maintained the pressure at 16 psi; the confirmation column inlet pressure was held at 80 psi for 2 min, and then 16 psi for the remainder of the run. A doubletapered $4 \mathrm{~mm}$ i.d. liner was used for the quantitation column, whereas a single-tapered $4 \mathrm{~mm}$ i.d. inlet liner packed with deactivated glass wool was used on the confirmation column. Both columns had a 1- $\mu \mathrm{L}$ injection volume.

Method Validation. Detector linearity was determined by linear regression analysis of five-point calibration curves (response versus concentration) for each analyte. After $r^{2} \geq$ 0.99 had been achieved, linear regression equations were used to quantify analytes in samples. Fortified blood samples (six levels including a blank) were prepared using the above procedure and analyzed by GC, and percent recoveries were determined for each analyte at each fortification level on two consecutive days (6). Method limits of detection (MLODs) were calculated from the $25 \mu \mathrm{g} / \mathrm{L}$ fortified blood and control chromatograms. MLODs were calculated as the quantity of analyte required to give a response of 3 times the baseline noise at the expected retention time of the analyte in the chromatogram of a nonfortified blood extract.

Quality Control. To ensure consistent instrument performance, prior to the GC analysis of any samples, a standard containing $100 \mu \mathrm{g} / \mathrm{L}$ endrin and $200 \mu \mathrm{g} / \mathrm{L}$ DDT was analyzed. For analysis to proceed, degradation was determined to be $\leq 20 \%$ for each compound and $\leq 30 \%$ for both compounds. Also, a $250 \mu \mathrm{g} / \mathrm{L}$ instrument calibration check standard was analyzed at the beginning, after every 10 samples, and at the end of each analytical run. The magnitude of response for all 10 analytes was required to match the response of the $250 \mu \mathrm{g} / \mathrm{L}$ standard in the calibration curve $\pm 25 \%$. Additionally, retention matches of \pm 0.05 min were required.

Surrogate recoveries were used to monitor individual sample extraction efficiency and instrument performance. In addition to analysis on the quantitation col umn, extracts of all samples found to contain OCPs were confirmed by GC analysis on the confirmation column.

\section{RESULTS AND DISCUSSION}

Chromatography. Due to the commercial unavailability of wildlife blood and plasma, chicken blood stabilized with the anticoagulant heparin was utilized for method development, validation, and quality control samples. Control chicken blood proved to be acceptable for these purposes as indicated by the lack of chromatographic responses at the retention times for the analytes of interest (Figure 2). Although the analysis of whole blood extracts produced more chromatographic peaks than plasma in the region of interest, none of the peaks interfered with any of the analytes of interest.

Method Validation. The results of the method validation experiments are presented in Table 1. For dieldrin, the analyte of primary concern, the mean recovery was $98.6 \%$ and the standard deviation was $5.7 \%$. Mean recoveries of the other analytes of primary concern, aldrin, endrin, p,p'-DDT, and p,p'-DDE, were $86.5 \pm 10,106 \pm 3.1,104 \pm 12$, and $96.0 \pm 8.9 \%$, respectively. Mean recovery of lindane, the compound added to all samples as a surrogate, was $97.0 \pm 4.3 \%$. This is similar to the $97.9 \pm 9.4 \%$ mean recovery for all compounds, indicating the suitability of lindane as a surrogate standard for these analyses. MLODs as calculated during method validation are presented in Table 2. The MLOD for dieldrin was $3.1 \mu \mathrm{g} / \mathrm{L}$. The MLODs for the other analytes of primary concern ranged from $1.1 \mu \mathrm{g} / \mathrm{L}$ for p,p'-DDT to $5.2 \mu \mathrm{g} / \mathrm{L}$ for endrin.

Comparison of Blood versus Plasma Methodology. Ten aliquots of $0.500 \mathrm{~mL}$ of chicken whole blood with heparin were fortified at $50 \mu \mathrm{g} / \mathrm{L}$ with the 10 compounds of concern. Two more ali quots to be used as controls were fortified with only the surrogate (lindane) at $250 \mu \mathrm{g} / \mathrm{L}$. Of the 12 whole blood samples fortified, 6 were extracted using the methodology for whole blood described in this paper. Six were centrifuged, and the resulting plasma was extracted using a previously published method (5). To summarize, plasma samples were transferred to a vacuum manifold containing conditioned C2 over C18 SPE columns in series. Three quality control plasma samples were added at this point. They were fortified at $50 \mu \mathrm{g} / \mathrm{L}$ and then extracted and assayed with the plasma samples to ensure the methodology was adequate because the sample size was 
$50 \mu \mathrm{g} / \mathrm{L}$ Fortified Chicken Whole Blood:

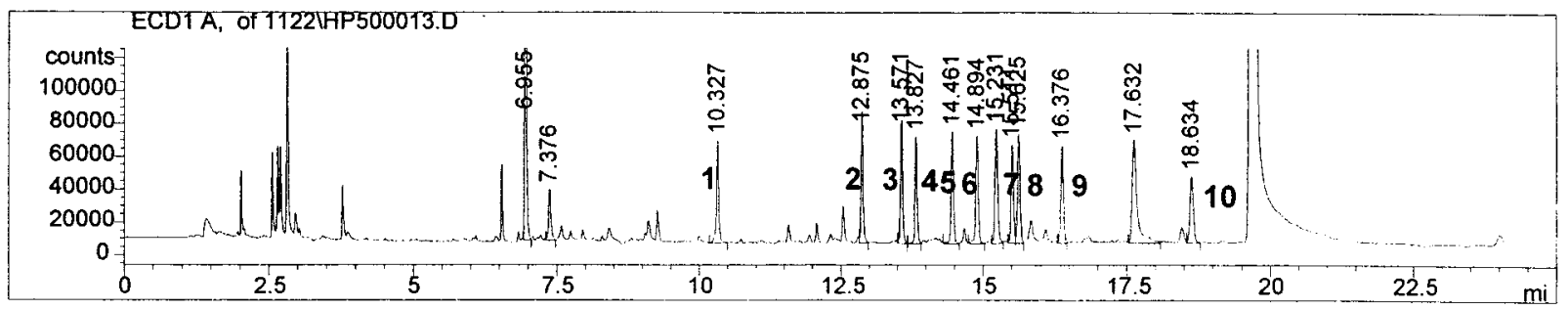

\section{Control Chicken Blood:}

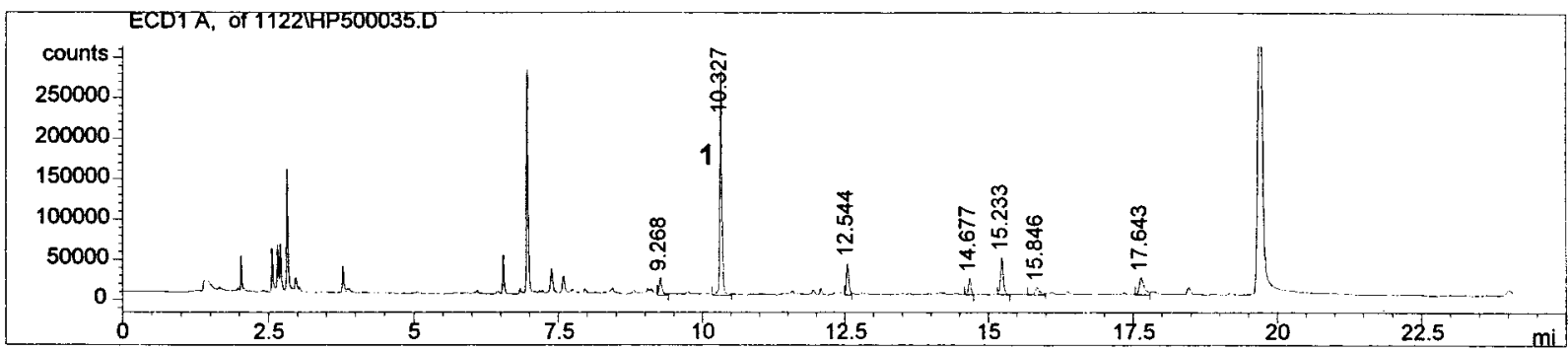

$50 \mu \mathrm{g} / \mathrm{L}$ Fortified Chicken Plasma:

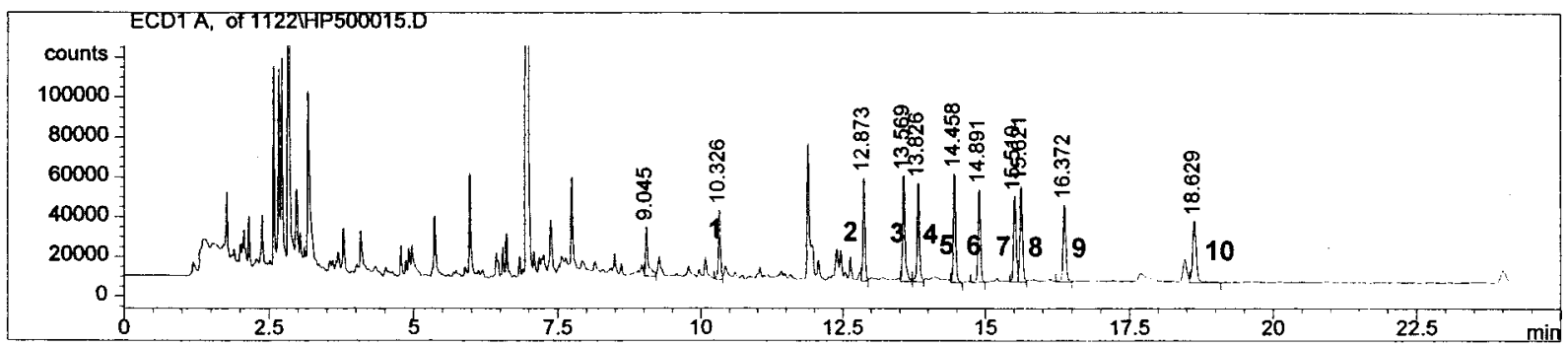

Control Chicken Plasma:

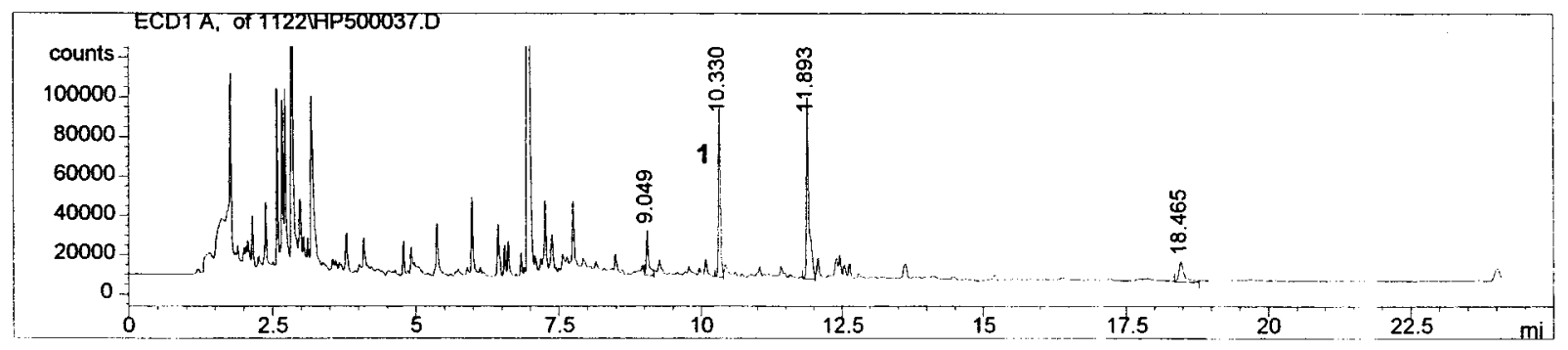

(1) lindane (surrogate), (2) aldrin, (3) isodrin, (4) heptachlor epoxide, (5) trans-chlordane, (6) cis-chlordane, (7) p,p'-DDE, (8) dieldrin, (9) endrin and (10) p,p'-DDT.

Figure 2. Chromatograms.

changed from 1.000 to $0.500 \mathrm{~mL}$. One milliliter of formic acid was added to each sample, which was then loaded onto the SPEs. The col umns were all owed to dry under vacuum. A silica SPE was added bel ow the C2 and C18 columns for sample cleanup, and the analytes were eluted with four 3-mL aliquots of 1:1 hexane/ether. Extracts were evaporated to $<0.500 \mathrm{~mL}$ and then reconstituted with hexane to $0.500 \mathrm{~mL}$. All samples were analyzed with the instrument parameters from the whole blood method.
The data presented in Figure 3 show that the analyte recoveries from whole blood were comparable to those observed from plasma. F our compounds, lindane, aldrin, cis-chlordane, and endrin, have better recoveries in whole blood. Least-squares means of the three sets of samples were graphed to make comparisons. Pairwise comparisons of least-squares means were performed using the Bonferroni method (7). Results indicated there were significant differences in blood and plasma recoveries for lindane, aldrin, cis-chlordane, and endrin. The 
Table 1. Method Validation Mean Percent Recoveries ${ }^{a}$

\begin{tabular}{|c|c|c|c|c|c|c|c|}
\hline compound & $25 \mu \mathrm{g} / \mathrm{L}$ & $50 \mu \mathrm{g} / \mathrm{L}$ & $100 \mu \mathrm{g} / \mathrm{L}$ & $250 \mu \mathrm{g} / \mathrm{L}$ & $500 \mu \mathrm{g} / \mathrm{L}$ & grand mean & SD \\
\hline lindane & 90.2 & 100 & 99.5 & 99.8 & 95.4 & 97.0 & 4.3 \\
\hline aldrin & 68.9 & 89.2 & 90.7 & 94.1 & 89.4 & 86.5 & 10 \\
\hline isodrin & 79.5 & 97.4 & 99.5 & 101 & 96.3 & 94.8 & 8.7 \\
\hline heptachlor epoxide & 82.0 & 96.1 & 103 & 101 & 95.5 & 95.5 & 8.2 \\
\hline trans-chlordane & 84.5 & 100 & 104 & 105 & 99.4 & 98.5 & 8.1 \\
\hline cis-chlordane & 80.9 & 104 & 109 & 108 & 104 & 101 & 12 \\
\hline$p, p^{\prime}-D D E$ & 80.9 & 96.2 & 101 & 104 & 98.5 & 96.0 & 8.9 \\
\hline dieldrin & 89.8 & 97.9 & 104 & 104 & 98.0 & 98.6 & 5.7 \\
\hline endrin & 107 & 103 & 110 & 109 & 103 & 106 & 3.1 \\
\hline$p, p^{\prime}-D D T$ & 86.2 & 98.5 & 111 & 115 & 110 & 104 & 12 \\
\hline
\end{tabular}

a Mean percent recoveries were calculated from quantitative and confirmation columns on two separate days $(n=4)$. The total mean recovery for all compounds equals $97.9 \pm 9.4 \%(n=50)$.

Table 2. Method Limits of Detection in Whole Blood

\begin{tabular}{lc}
\hline \multicolumn{1}{c}{ compound } & av MLOD $(\mu \mathrm{g} / \mathrm{L})$ \\
\hline lindane & not calcd-surrogate spiked in control samples \\
aldrin & 4.2 \\
isodrin & 2.1 \\
heptachlor epoxide & 1.4 \\
trans-chlordane & 2.3 \\
cis-chlordane & 4.2 \\
p, $p^{\prime}$-DDE & 2.1 \\
dieldrin & 3.1 \\
endrin & 5.2 \\
p.p'-DDT & 1.1
\end{tabular}

a MLODs were calculated using a control and a whole blood sample fortified at $25 \mu \mathrm{g} / \mathrm{L}$, assayed on two separate days on the quantitation column $(n=2)$.

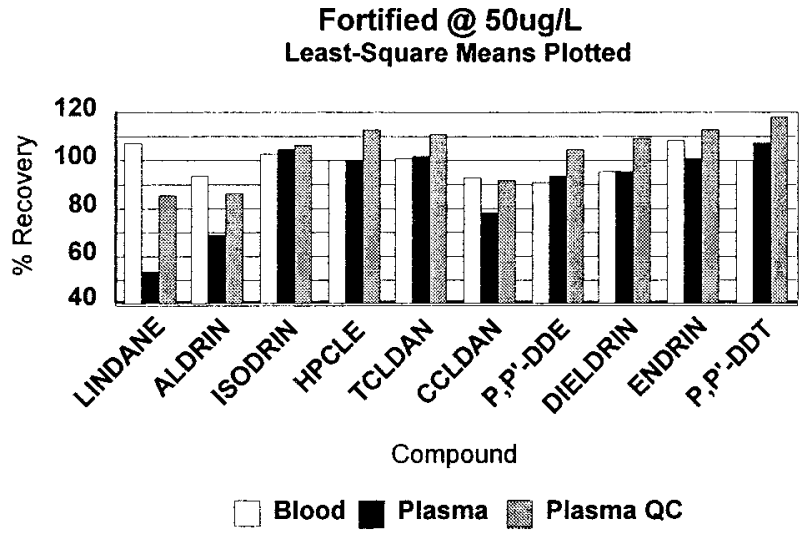

HPCLE=Heplachlor epoxide, TCLDAN=Trans-chlordane, CCLDAN=Cis-chlordane

Figure 3. Percent recovery for whole blood and plasma methodologies.

blood method was more efficient in recovering these compounds, possibly due to analyte loss when the plasma was separated from blood cells. There were also significant differences in plasma and plasma quality control recoveries for lindane, aldrin, and cis-chlordane. This further supports the assumption that some analytes may be lost when the plasma is separated.

Table 3 shows MLODs for the two methods. The MLOD for plasma was higher than for whole blood in every case but endrin. This comparison suggests that the blood method was generally more sensitive than the plasma method. However, an analysis of variance indicated a strong relationship between compound and matrix interactions. This suggests that the MLOD depends on the matrix and compound. As indicated in Table 3, the MLOD for isodrin in blood is $3.0 \mathrm{mg} / \mathrm{L}$, whereas that for plasma is $22 \mathrm{mg} / \mathrm{L}$; however, that for heptachlor epoxide in blood is $2.6 \mathrm{mg} / \mathrm{L}$, whereas in plasma it is $2.7 \mathrm{mg} / \mathrm{L}$.
Table 3. Method Limits of Detection in Chicken Whole Blood and Plasma ${ }^{a}$

\begin{tabular}{lcc}
\hline \multirow{2}{*}{\multicolumn{1}{c}{ compound }} & \multicolumn{2}{c}{ MLOD $(\mu \mathrm{g} / \mathrm{L})$} \\
\cline { 2 - 3 } lindane & whole blood & plasma \\
aldrin & not cal-surrogate spiked in control samples \\
isodrin & 3.1 & 7.6 \\
heptachlor epoxide & 3.0 & 22 \\
trans-chlordane & 2.6 & 2.7 \\
cis-chlordane & 2.5 & 4.8 \\
p,p'-DDE & 1.8 & 2.8 \\
dieldrin & 1.4 & 4.6 \\
endrin & 2.1 & 2.7 \\
p,p'-DDT & 9.6 & 4.9 \\
& 2.1 & 4.1
\end{tabular}

a MLODs were calculated using a control and samples fortified at $50 \mu \mathrm{g} / \mathrm{L}(\mathrm{n}=5)$.

The data presented here suggest that the preparation of plasma prior to analysis for quantification of OCPS is unnecessary and may produce some analyte partitioning, which can influence the amount of OCP observed in a sample. The whole blood methodology permits collection of smaller blood volumes than is required for plasma analysis and is more amenable to smaller species (for which the quantity of blood is limited) and is therefore more broadly applicable to a wider range of wildlife species. This approach could be applied to the analysis of other pesticides, drugs, and organic contaminants in wildlife.

\section{ACKNOWLEDGMENT}

Critical review of the manuscript by J erry Hurley was appreciated.

\section{LITERATURE CITED}

(1) Atuma, S. S.; Aune, M. Method for the Determination of PCB Cogeners and Chlorinated Pesticides in Human Blood Serum. Bull. Environ. Contam. Toxicol. 1999, 62, 8-15.

(2) Mes, J .; Barchand, L.; Turton, D.; Lau, P.-Y. The Determination of Polychlorinated Biphenyl Congeners and Other Chlorinated Hydrocarbon Residues in Human Blood, Serum and Plasma. A Comparative Study. Int. J . Environ. Anal. Chem. 1992, 48, 175-186.

(3) Pauwels, A.; Schepens, P. J . C. Simultaneous Separation and Determination of Polychlorinated Biphenylcogeners and Other Chlorinated Hydrocarbon Residues in Human Matrices Using Gel Permeation or Adsorption Chromatographic Clean-Up and GC-MS Quantification. Int. J . Environ. Anal. Chem. 1998, 71 (2), 105-118.

(4) Pauwels, A.; Wells, D. A.; Covaci, A.; Schepens, P. J . C. Improved sample preparation method for selected persistent organochlorine pollutants in human serum using solid-phase disk extraction with gas chromatographic analysis. J . Chromatogr. B 1999, 723, 117-125. 
(5) J ohnston, J . J .; Petty, E. E.; Volz, S. A. Solid Phase Extraction GC/ECD Method for the Analysis of Organochlorine Pesticides in Wildlife Plasma. J. High Resolut. Chromatogr. 1997, 20 (Aug), 405-409.

(6) Rocky Mountain Arsenal; Chemical Quality Assurance Plan, version 1.0, 2nd ed.; April 1996.

(7) SAS Institute Inc. SAS/ STAT User's Guide, version 6, 4th ed.; SAS I nstitute: Cary, NC, 1989; Vol. 2, pp 942943.
Received for review September 27, 2000. Revised manuscript received April 2, 2001. Accepted April 14, 2001. Mention of commercial products is for identification only and does not constitute endorsement by the U.S. government.

JF001182J 